\title{
Deposition and Resuspension
} Mechanisms Into and From Tree Canopies: A Study Modeling Particle Removal of Conifers and Broadleaves in Different Cities

\section{OPEN ACCESS}

Edited by:

Mark Potosnak

DePaul University, United States

Reviewed by:

Ana Maria Yáñez-Serrano, Ecological and Forestry Applications Research Center (CREAF), Spain

Robert Popek,

Warsaw University of Life

Sciences, Poland

*Correspondence:

Rüdiger Grote

ruediger.grote@kit.edu

Specialty section: This article was submitted to Forests and the Atmosphere, a section of the journal Frontiers in Forests and Global Change

Received: 17 July 2019 Accepted: 24 February 2020 Published: 12 March 2020

Citation:

Pace $R$ and Grote $R$ (2020) Deposition and Resuspension Mechanisms Into and From Tree Canopies: A Study Modeling Particle Removal of Conifers and Broadleaves in Different Cities. Front. For. Glob. Change 3:26. doi: 10.3389/ffgc.2020.00026

\author{
Rocco Pace and Rüdiger Grote* \\ Institute of Meteorology and Climate Research - Atmospheric Environmental Research (IMK-IFU), Karlsruhe Institute of \\ Technology (KIT), Karlsruhe, Germany
}

With increasing realization that particles in the air are a major health risk in urban areas, strengthening particle deposition is discussed as a means to air-pollution mitigation. Particles are deposited physically on leaves and thus the process depends on leaf area and surface properties, which change throughout the year. Current state-of-the-art modeling accounts for these changes only by altering leaf longevity, which may be selected by vegetation type and geographic location. Particle removal also depends on weather conditions, which determine deposition and resuspension but generally do not consider properties that are specific to species or plant type. In this study, we modeled $<$ $2.5 \mu \mathrm{m}$-diameter particulate-matter $\left(\mathrm{PM}_{2.5}\right)$ deposition, resuspension, and removal from urban trees along a latitudinal gradient (Berlin, Munich, Rome) while comparing coniferous with broadleaf (deciduous and evergreen) tree types. Accordingly, we re-implemented the removal functionality from the i-Tree Eco model, investigated the uncertainty connected with parameterizations, and evaluated the efficiency of pollution mitigation depending on city conditions. We found that distinguishing deposition velocities between conifers and broadleaves is important for model results, i.e., because the removal efficiency of conifers is larger. Because of the higher wind speed, modeled $\mathrm{PM}_{2.5}$ deposition from conifers is especially large in Berlin compared to Munich and Rome. Extended periods without significant precipitation decrease the amount of $\mathrm{PM}_{2.5}$ removal because particles that are not occasionally washed from the leaves or needles are increasingly resuspended into the air. The model predicted this effect particularly during the long summer periods in Rome with only very little precipitation and may be responsible for less-efficient net removal from urban trees under climate change. Our analysis shows that the range of uncertainty in particle removal is large and that parameters have to be adjusted at least for major tree types if not only the species level. Furthermore, evergreen trees (broadleaved as well as coniferous) are predicted to be more effective at particle removal in northern regions than in Mediterranean cities, which is unexpected given the higher number of evergreens in southern cities. We discuss to what degree the effect of current $\mathrm{PM}_{2.5}$ abundance can be mitigated by species selection and which model improvements are needed.

Keywords: air quality, model evaluation, urban trees, deposition velocities, resuspension, metropolitan areas 


\section{INTRODUCTION}

The high concentration of particulate matter in the air is a problem relevant to human health, particularly in urban areas (World Health Organization, 2013). All combustion processes (such as by vehicle engines or furnaces for heating of buildings) contribute to the emission of fine particles $(<10 \mu \mathrm{m}$ diameter), which represent a considerable hazard for people because they can penetrate deep into the lung tissue and enter the bloodstream (World Health Organization, 2006). The European Union set concentration limits for different sizes of particulate matter (PM) to be $40 \mu \mathrm{g} \mathrm{m}^{-3} \mathrm{yr}^{-1}$ for $\mathrm{PM}_{10}$ and $25 \mu \mathrm{g} \mathrm{m}^{-3} \mathrm{yr}^{-1}$ for $\mathrm{PM}_{2.5}$ (European Commission, 2008), but these are often exceeded in many European cities, demanding considerable measures to improve air quality (European Environment Agency, 2018). Recently, the European Commission has suggested application of the nature-based solutions concept, which includes preserving, managing, and restoring natural or modified ecosystems in order to respond to societal challenges and contribute to the human well-being and biodiversity (European Commission, 2015). A recommendation for the practical implementation of naturebased solutions is to design green infrastructures (Hansen et al., 2019), which are very efficient in providing ecosystem services for animals and people (Calfapietra and Cherubini, 2019).

Trees remove airborne PM by deposition on leaf, bark, and branch surfaces that is later on washed off by rainfall or deposited on the ground with senescent tissue (Beckett et al., 1998; Janhäll, 2015; Cai et al., 2017). Although bark and branches can substantially contribute to total deposition, smaller particles are preferentially captured by foliage (Xu et al., 2019). Thus, deciduous trees remove pollutants from the air primarily during the vegetative (leaf-on) period, which is a relatively short period compared to the whole year of activity by evergreen plants. The length of the vegetative period varies by geographic location because it is mainly controlled by light and temperature (Badeck et al., 2004; Forrest and Miller-Rushing, 2010). The capacity to remove fine PM depends on the leaf area, also considering phenological transition phases (Wang et al., 2015) as well as on leaf surface properties that are species-specific (Sæbø et al., 2012; Zhang W. et al., 2017; Shao et al., 2019). The actual deposition rate is then modified by weather conditions, such as wind speed or precipitation regime (Schaubroeck et al., 2014) as well as pollution concentration (Lu et al., 2018). Needles of conifers are considered more efficient than broadleaves in removing fine PM because of their shape, abundance of waxes on their surfaces, and their surface structure (Chen et al., 2017; Zhang W. et al., 2017; Muhammad et al., 2019). Species-specific foliage properties also determine how strongly deposited particles are stuck to the leaf and how easily they are resuspended into the air (Blanusa et al., 2015; Chen et al., 2017; Zhang W. et al., 2017).

However, deposition models such as i-Tree Eco (Hirabayashi et al., 2015) use one single value for deposition velocity and assume the same resuspension behavior for all tree types. The only difference that may be considered between deciduous and evergreen trees is related to the amount and duration of leaf area (Tiwary et al., 2016). This limitation is due to the uncertainty of quantification of leaf-property impacts, mostly because of the absence of measurements for many species. Also, if measurements are available, they are not recorded under standardized environmental boundary conditions. Therefore, models generally cannot be run with species-specific parameters; instead, values may be selected rather arbitrarily (Peters and Eiden, 1992; Lovett, 1994).

To estimate the relative performance of coniferous and broadleaved trees (deciduous and evergreen), we investigated the sensitivity of calculated fine particle $\left(\mathrm{PM}_{2.5}\right)$ removal to parameter settings in different environments along a latitudinal gradient that also represents a gradient in temperature and precipitation (Berlin, Munich, and Rome) during 2013-2015. The range of locations provides differences in precipitation, wind speed, and air pollution, which are likely to influence the extent of deposition and resuspension. We are therefore addressing the following objectives: (1) Investigating the dependence of mechanisms related to net pollution removal (deposition, washing, and resuspension) on climate. With this objective we are also investigating responses under potential climate changes which are likely to be accompanied with changes in rainfall patterns favoring long dry and warm periods (Giannakopoulos et al., 2009). (2) Assessing the impact of pollution levels and temporal dynamics on net particle removal by tree types which differ in basic foliage properties (Xiao et al., 2015). Based on the results, we will finally discuss how species selection can affect pollution removal performances in the three cities and suggest model modifications to improve the representation of deposition, resuspension, and removal of particulate matter.

\section{METHODS}

\section{Model Description}

We calculated the deposition flux of $\mathrm{PM}_{2.5}$ according to the method used in the i-Tree Eco model (Hirabayashi et al., 2015):

$$
\begin{aligned}
f_{t} & =V d_{t} \times C \times L A I \times 3600 \\
R_{t} & =\left(A_{t-1}+f_{t}\right) \times \frac{r r_{t}}{100} \\
A_{t} & =\left(A_{t-1}+f_{t}\right)-R_{t} \\
F_{t} & =f_{t}-R_{t}
\end{aligned}
$$

where $\mathrm{f}_{\mathrm{t}}$ is the $\mathrm{PM}_{2.5}$ flux at time $\mathrm{t}\left(\mathrm{g} \mathrm{m}^{-2} \mathrm{~h}^{-1}\right), \mathrm{C}$ is pollutant concentration $\left(\mathrm{g} \mathrm{m}^{-3}\right)$, and $\mathrm{Vd}_{\mathrm{t}}$ is the deposition velocity at time $\mathrm{t}\left(\mathrm{m} \mathrm{s}^{-1}\right)$ that is calculated from the wind speed (windSp) as $v d s$ $\times$ windSp $\mathrm{p}^{x}$, with $v d s$ being the "specific deposition velocity." It should be noted that this model neglects the deposition on bark and branches for simplification reasons. The values are based on regression equations that are developed from the literature specifically for each tree type (see next paragraph), $\mathrm{C}$ is the $\mathrm{PM}_{2.5}$ air concentration $\left(\mathrm{g} \mathrm{m}^{-3}\right)$, LAI is the leaf-area index, $\mathrm{R}_{\mathrm{t}}$ is the $\mathrm{PM}_{2.5}$ flux resuspended in the atmosphere at time $\mathrm{t}\left(\mathrm{g} \mathrm{m}^{-2}\right.$ $\left.\mathrm{h}^{-1}\right), \mathrm{A}_{\mathrm{t}-1}$ is the $\mathrm{PM}_{2.5}$ accumulated on leaves at time $\mathrm{t}\left(\mathrm{g} \mathrm{m}^{-2}\right.$ $\mathrm{h}^{-1}$ ) depending on previous deposition as well as precipitation, $r r_{\mathrm{t}}$ is the relative amount deposited $\mathrm{PM}_{2.5}$ that is resuspended at a specific wind speed at time $\mathrm{t}(\%)$ which has been defined 
TABLE 1 | Deposition velocities for different wind-speed classes for deciduous broadleaved trees derived from published data.

\begin{tabular}{|c|c|c|c|c|c|}
\hline Wind speed $\left(\mathrm{m} \mathrm{s}^{-1}\right)$ & 1 & 3 & 6 & 8.5 & 10 \\
\hline Quercus petraea (Matt.) Liebl. ${ }^{1}$ & & 0.831 & 1.757 & 3.134 & \\
\hline Alnus glutinosa (L.) Gaertner ${ }^{1}$ & & 0.125 & 0.173 & 0.798 & \\
\hline Fraxinus excelsior (L.) $)^{1}$ & & 0.178 & 0.383 & 0.725 & \\
\hline Eucalyptus globulus (Labill.) ${ }^{1}$ & & 0.018 & 0.029 & 0.082 & \\
\hline Ficus microcarpa (L.) ${ }^{1}$ & & 0.041 & 0.098 & 0.234 & \\
\hline Acer campestre $(\mathrm{L} .)^{2}$ & 0.03 & 0.08 & & 0.46 & 0.57 \\
\hline Sorbus intermedia (Ehrh.) Pers. ${ }^{2}$ & 0.04 & 0.39 & & 1.82 & 2.11 \\
\hline Populus deltoides $x$ trichocarpa (Beaupré) ${ }^{2}$ & 0.03 & 0.12 & & 1.05 & 1.18 \\
\hline Average & 0.03 & 0.22 & 0.49 & 1.04 & 1.29 \\
\hline
\end{tabular}

${ }^{1}$ Freer-Smith et al., 2004; ${ }^{2}$ Beckett et al., 2000.

according to the i-tree model standards (see Table S2 and next paragraph), and $F_{t}$ is the net $\mathrm{PM}_{2.5}$ removal at time $t$ after considering resuspension.

Deposition velocities are described as a function of wind speed, which we derived from prior-published measurements (Beckett et al., 2000; Freer-Smith et al., 2004; Pullman, 2009). First, we separated measurements into those carried out at conifers and those at broadleaf trees (Tables 1, 2). Then, we developed regression functions separately for the coniferous and broadleaf tree type, relating velocity and wind speed (Figure 1). For broadleaf evergreen trees (mostly species originating from southern Europe), we assumed the same deposition velocity as that of broadleaf deciduous trees because the deposition process seems to depend more on leaf shape (needle vs. flat leaf) than on other differences that might characterize evergreen vs. deciduous broadleaves. In any case, literature information is not sufficient to derive a separate function for evergreen broadleaves. With this differentiation, our model approach varies from the original i-Tree model which only uses one relation for all trees (and one that is similar to that of broadleaf trees). Resuspension also depends on wind speed. As in the i-Tree Eco model, a specific resuspension rate is assumed for each of 13 specific wind speed classes $\left(r r_{t}\right)$. This stepwise dependency function has first been described in the i-Tree Eco documentation (Hirabayashi et al., 2015). Finally, washing from the leaves (and thus final deposition) is calculated when precipitation events are higher than the maximum water storage capacity of the canopy, which is defined by potential leaf water storage plws $\left(\mathrm{mm} \mathrm{m}^{-2}\right)$ (leaf water storage $=$ plws $\times \mathrm{LAI}$ ). If such an event occurs, all $\mathrm{PM}_{2.5}$ accumulated on leaves is assumed to be washed off and $A_{t-1}$ is set to 0 (Hirabayashi et al., 2015).

\section{Site-Specific Parameterization}

Apart from general parameterizations that are assumed valid for all tree types and sites, phenology parameters are set specifically for the investigated region. This includes the following parameters: (1) "maximum LAI" which is the LAI value achieved in the vegetation period when leaves are fully developed and not senescent; (2) leaf-on and leaf-off dates that indicate the start of flushing or leaf senescence, respectively; and
TABLE 2 | Deposition velocities for different wind-speed classes for coniferous trees derived from published data.

\begin{tabular}{|c|c|c|c|c|c|}
\hline Wind speed $\left(\mathrm{m} \mathrm{s}^{-1}\right)$ & 1 & 3 & 6 & 8.5 & 10 \\
\hline $\begin{array}{l}\text { Pseudotsuga menziesii (Mirb.) } \\
\text { Franco }^{1}\end{array}$ & & 1.269 & 1.604 & 6.04 & \\
\hline Pinus nigra (Arnold) $)^{2}$ & 0.13 & 1.15 & & 19.24 & 28.05 \\
\hline $\begin{array}{l}\text { Cupressocyparis } \times \text { lexlandii } \\
(\text { Dallim. })^{2}\end{array}$ & 0.08 & 0.76 & & 8.24 & 12.2 \\
\hline Pinus strobus (L.) $)^{3}$ & 0.0108 & & & & \\
\hline Tsuga canadensis (L.) Carrière ${ }^{3}$ & 0.0193 & & & & \\
\hline $\begin{array}{l}\text { Pseudotsuga japonica (Shiras.) } \\
\text { Beissn. }^{3}\end{array}$ & 0.0058 & & & & \\
\hline Picea abies (L.) Karst. ${ }^{3}$ & $0.0189-0.038$ & & & & \\
\hline Average & 0.04 & 1.06 & 1.60 & 11.1 & 20.1 \\
\hline
\end{tabular}

${ }^{1}$ Freer-Smith et al., 2004; ${ }^{2}$ Beckett et al., 2000; ${ }^{3}$ Pullman, 2009.

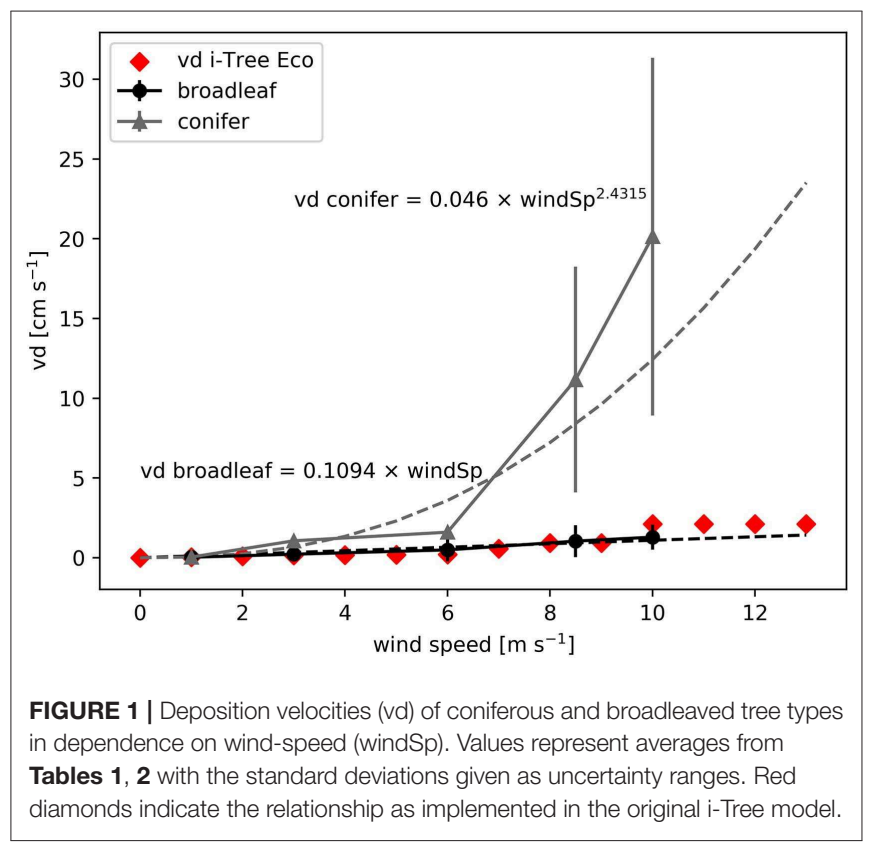

(3) the length of the transition periods. We parameterized leafon and leaf-off dates as the average of the dates of first and last frost events (www.weatheronline.co.uk). For Berlin, the day-ofyear (doy) leaf-on and leaf-off dates are April 2nd (doy 92) and November 1st (doy 305); for Munich, April 5th (doy 95) and November 4th (doy 308); and for Rome, February 27th (doy 58) and December 2nd (doy 336). Furthermore, we assumed a maximum LAI of 3 and a 30-days transition period in the spring and fall, during which trees gradually produce or lose foliage. The maximum LAI has been set equal to all tree types despite conifers are usually considered to have a higher LAI (more than 6) than broadleaf trees (around 3-5) (Teske and Thistle, 2004; Peters et al., 2010). However, LAI in urban areas has been determined as considerably lower than in closed woodlands (Klingberg et al., 2017) with air pollution being a possible reason (Gratani and Varone, 2007). In fact, values for deciduous trees are commonly reported to be around 3 (Gratani and Varone, 2007; Öztürk 
TABLE 3 | Seasonal and yearly $\mathrm{PM}_{2.5}$ average concentration.

\begin{tabular}{|c|c|c|c|c|c|c|c|c|c|c|c|c|c|c|c|}
\hline \multirow{2}{*}{$\begin{array}{l}\mathrm{PM}_{2.5} \\
\left(\mu \mathrm{g} \mathrm{m}^{-3}\right)\end{array}$} & \multicolumn{5}{|c|}{2013} & \multicolumn{5}{|c|}{2014} & \multicolumn{5}{|c|}{2015} \\
\hline & Winter & Spring & Summer & Autumn & Year & Winter & Spring & Summer & Autumn & Year & Winter & Spring & Summer & Autumn & Year \\
\hline Berlin & 24.7 & 16.1 & 10.9 & 14.9 & 16.7 & 28.7 & 15.4 & 14.0 & 25.4 & 20.9 & 21.7 & 13.5 & 13.2 & 19.4 & 16.9 \\
\hline Munich & 20.5 & 17.0 & 11.0 & 14.8 & 15.8 & 16.8 & 12.4 & 11.2 & 12.9 & 13.3 & 16.1 & 11.9 & 11.6 & 13.0 & 13.2 \\
\hline Rome & 21.4 & 12.3 & 12.8 & 20.0 & 16.6 & 19.7 & 11.9 & 11.3 & 19.5 & 15.6 & 19.6 & 12.5 & 12.8 & 22.0 & 16.7 \\
\hline
\end{tabular}

TABLE 4 | Seasonal and yearly cumulative precipitation.

\begin{tabular}{|c|c|c|c|c|c|c|c|c|c|c|c|c|c|c|c|}
\hline \multirow{2}{*}{$\begin{array}{l}\text { Rain } \\
(\mathrm{mm})\end{array}$} & \multicolumn{5}{|c|}{2013} & \multicolumn{5}{|c|}{2014} & \multicolumn{5}{|c|}{2015} \\
\hline & Winter & Spring & Summer & Autumn & Year & Winter & Spring & Summer & Autumn & Year & Winter & Spring & Summer & Autumn & Year \\
\hline Berlin & 98 & 154 & 168 & 143 & 564 & 54 & 137 & 158 & 69 & 418 & 88 & 81 & 132 & 158 & 458 \\
\hline Munich & 114 & 276 & 213 & 134 & 737 & 59 & 158 & 306 & 164 & 688 & 88 & 319 & 119 & 136 & 662 \\
\hline Rome & 285 & 123 & 27 & 270 & 706 & 343 & 108 & 128 & 315 & 893 & 212 & 110 & 86 & 154 & 562 \\
\hline
\end{tabular}

TABLE 5 | Seasonal and yearly average wind speed.

\begin{tabular}{|c|c|c|c|c|c|c|c|c|c|c|c|c|c|c|c|}
\hline \multirow{2}{*}{$\begin{array}{l}\text { Wind speed } \\
\left(\mathrm{m} \mathrm{s}^{-1}\right)\end{array}$} & \multicolumn{5}{|c|}{2013} & \multicolumn{5}{|c|}{2014} & \multicolumn{5}{|c|}{2015} \\
\hline & Winter & Spring & Summer & Autumn & Year & Winter & Spring & Summer & Autumn & Year & Winter & Spring & Summer & Autumn & Year \\
\hline Berlin & 3.4 & 3.2 & 2.9 & 3.5 & 3.3 & 3.8 & 3.1 & 2.9 & 3.4 & 3.3 & 4.0 & 3.6 & 3.6 & 3.7 & 3.7 \\
\hline Munich & 3.1 & 2.9 & 2.4 & 2.6 & 2.7 & 2.6 & 2.7 & 2.6 & 2.9 & 2.7 & 3.5 & 3.1 & 2.5 & 3.1 & 3.1 \\
\hline Rome & 2.6 & 2.3 & 2.0 & 2.0 & 2.2 & 2.3 & 2.1 & 2.1 & 2.0 & 2.1 & 2.2 & 2.1 & 1.9 & 1.8 & 2.0 \\
\hline
\end{tabular}

et al., 2015; Massetti et al., 2019). On the other hand, pines, which are the most abundant conifers in the Mediterranean region (Grote et al., 2016) as well as in the forests around Berlin (Tigges et al., 2017) are also assumed to have a leaf area around 3 (Bréda, 2003). The same holds for evergreen oaks, which are representative for Mediterranean broadleaf evergreen trees (Escudero and Mediavilla, 2003). For this reason, we set LAI to 3 for all tree types although we acknowledge that regional and species-specific variation is relatively large.

\section{Driving Variable Derivation}

$\mathrm{PM}_{2.5}$-concentration data were taken from the i-Tree Eco database, which contains pollution data from the European Environmental Agency. The pollution level is similar in all three cities, with Berlin having slightly higher concentrations, particularly in 2014 (Table 3). Seasonality of $\mathrm{PM}_{2.5}$ concentration is not very expressed in either of the sites, but the pollution minimum is in the summer, while the highest $\mathrm{PM}_{2.5}$ concentrations occur in the winter (except in 2015 in Rome, which had the highest concentrations in autumn). The reason for the maximum in winter is the increased residential heating and the longer lifetime of PM precursors. Hourly precipitation and wind-speed data were selected from airport-station records in Berlin (Tegel) and Munich (München-Flughafen) and from the weather station in Castelporziano for Rome. These weather stations are all located at the city border, some distance from the city centers. We assume that a similar relative position is better suited for our purpose to compare the different locations, since wind speed is considerably heterogeneous within a city (Levy and Hanna, 2011; Drew et al., 2013). In Rome, spring, and summer precipitation is considerably lower than that in the winter and autumn, while the situation is almost the opposite in Munich, where the highest rainfalls occur in the spring. The overall precipitation in Berlin is about a third less than that at the other two sites (Table 4). Also, there is a clear gradient in wind speed from Berlin to Munich and Rome, with the highest air movements mostly in the autumn and winter and the lowest in the summer. In Rome, there is hardly any seasonal variation, unlike at the German sites, which show some growing-season variation (Table 5). Modeling simulations were performed for the years 2013-2015.

\section{RESULTS}

We found that the highest $\mathrm{PM}_{2.5}$ deposition was in Berlin, followed by Munich and Rome. The difference is particularly large for conifers, which remove seven times more air pollutants than the broadleaf deciduous trees in Berlin, and about five times more than in Munich and Rome, respectively (Table 6). In relative terms, the broadleaf evergreen trees remove twice as much air pollutants as broadleaf deciduous trees. The difference is smallest in Munich (factor 1.8) and largest in Rome (factor 2.5) with Berlin close to Munich (factor 2.1). Also, the data show inter-annual differences of $\pm 24 \%$ over the 3 years for conifers, $\pm 7 \%$ broadleaf evergreens, and $\pm 2 \%$ broadleaf deciduous, indicating that not only species properties but also air-pollution 
TABLE 6 | Annual $\mathrm{PM}_{2.5}$ removal by different tree types in three cities.

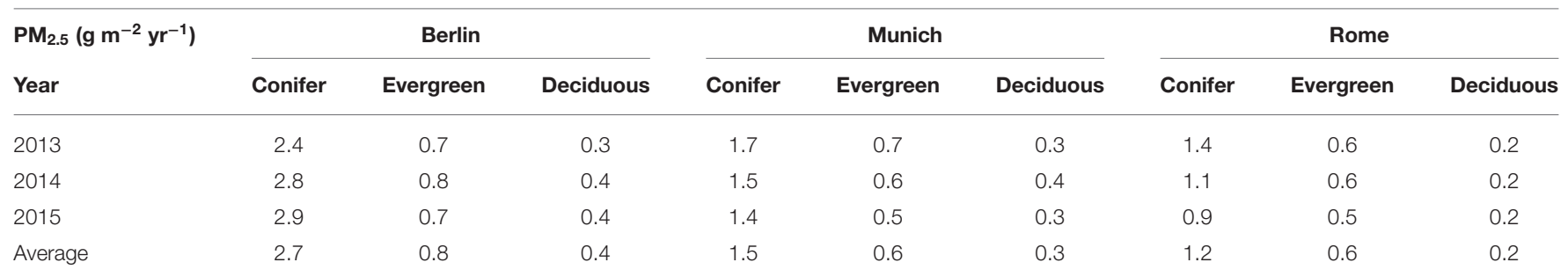

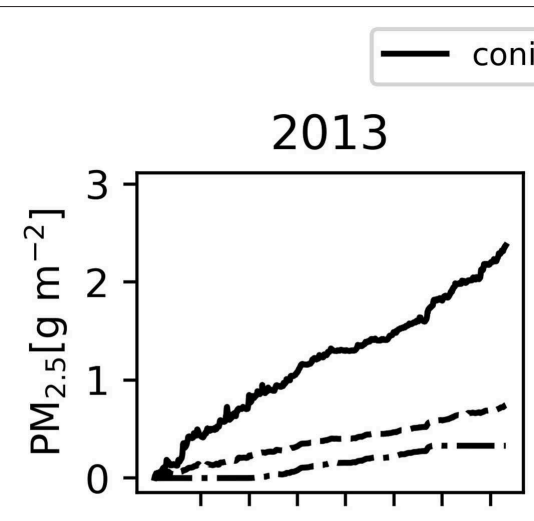

\section{conifer - - evergreen -. deciduous}
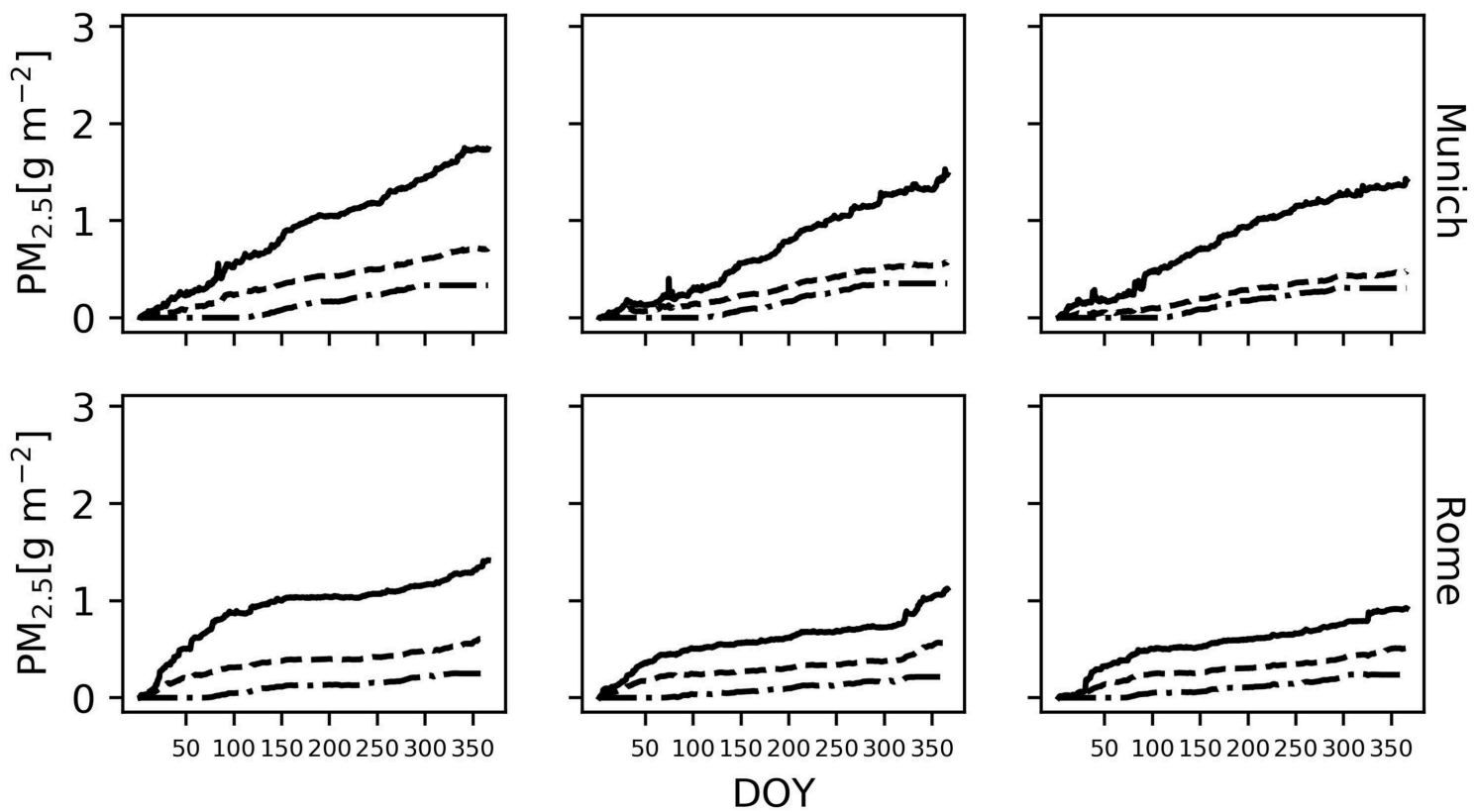

FIGURE 2 | PM 2.5 cumulative net removal per unit ground cover in Berlin, Munich, and Rome. Decreasing slopes indicate periods of resuspension. For better comparison, leaf surfaces are assumed as empty at the start of each year.

distribution and seasonal weather conditions are influencing PM removal (Table 6, Figure 2).

Since bark and branch deposition is not considered, deciduous trees do not deposit particles outside the vegetation period, i.e., in the winter (the deposition in Rome during this time occurs because the vegetation period here prolongs into the winter period). For the other two tree types, the seasonal pattern is similar for Berlin and Rome, with the highest deposition rates in the autumn and winter, but different for Munich, where these months are often those with the lowest deposition rates (with some exceptions, e.g., high removal rate for Berlin in summer 2015, for Rome in spring 2013, and for Munich in autumn 2013) (Figure 3). A closer look at the daily net removal rates shows that it is in a range between -0.01 and $0.02 \mathrm{~g} \mathrm{~m}^{-2} \mathrm{~h}^{-1}$ for conifers which perform maximum deposition rates of up to $0.04 \mathrm{~g} \mathrm{~m}^{-2} \mathrm{~h}^{-1}$ obtained in Munich, summer 2014 (as shown in 

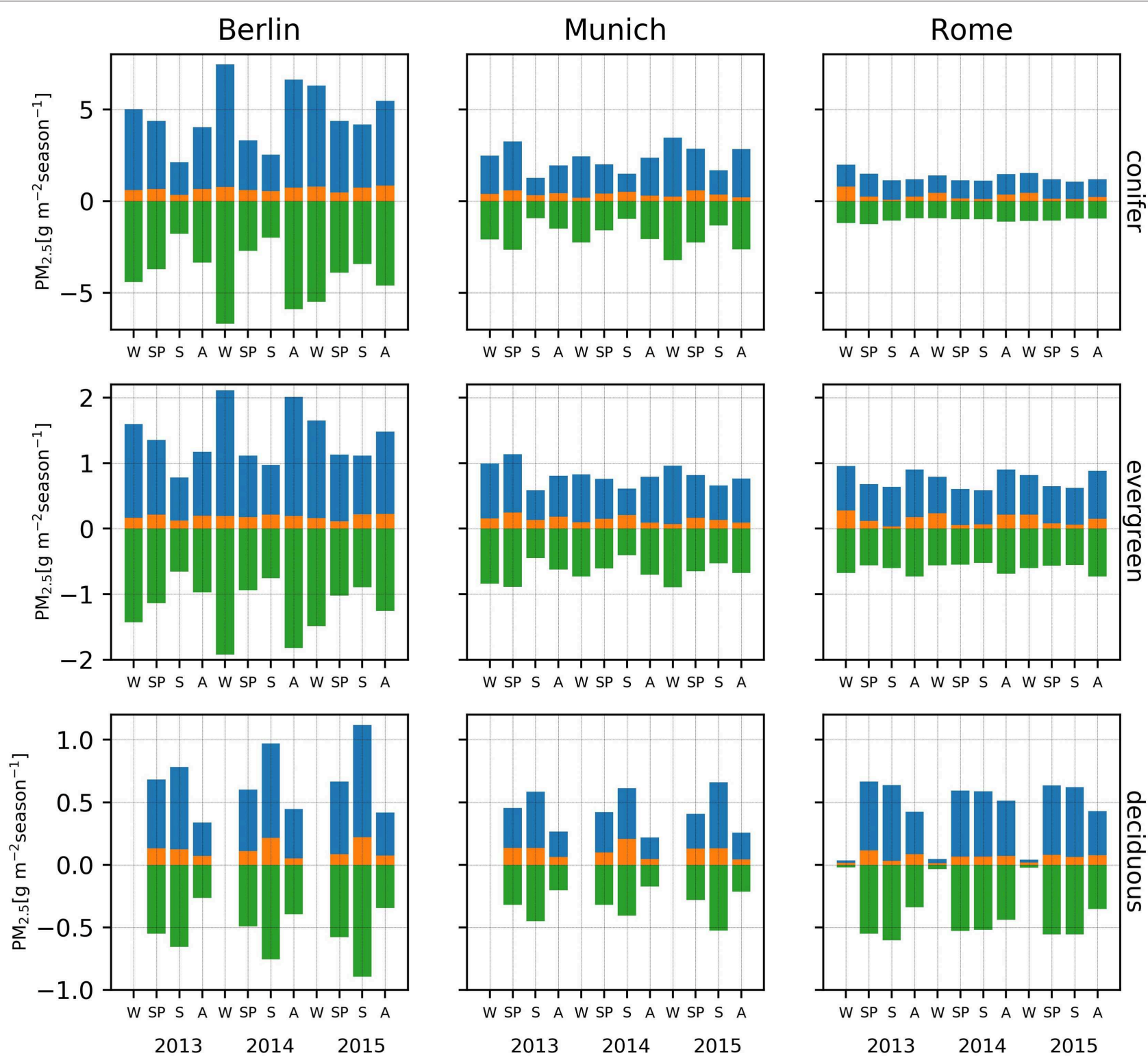

deposition

$2013 \quad 2014 \quad 2015$

resuspension

FIGURE 3 | Seasonal PM 2.5 deposition, removal, and resuspension for three cities, 2013-2015 [seasons: W, winter; SP, spring; S, summer; A, autumn].

Figure S1). For evergreen broadleaf trees the net removal only varies between -0.002 and $+0.002 \mathrm{~g} \mathrm{~m}^{-2} \mathrm{~h}^{-1}$ and is even smaller for deciduous broadleaf trees $\left(-0.001\right.$ and $\left.+0.001 \mathrm{~g} \mathrm{~m}^{-2} \mathrm{~h}^{-1}\right)$ (see Figures S1-S3).

There are only very few measurements that can serve to evaluate the calculations presented here. Fares et al. (2016) carried out an eddy-flux investigation of deposition in Rome on a Holm oak (Quercus ilex L.) forest during 2 years that are also part of our analysis (2014 and 2015). The averaged data from the measurements during the whole vegetation period are thus shown together with the calculated mean diurnal flux of $\mathrm{PM}_{2.5}$ into and from the canopy (see Figure S4).
The calculated deposition increases during the day with a peak at mid-day, closely following the development of wind speed. In parallel also resuspension rises because it depends on deposition. In the absence of rainfall, as in the case of Rome in summer, particulate matter is not washed off from leaves which leads to large accumulation, increased resuspension, and thus to negative values of net removal in particular during the middle hours of the day since it is more sensitive to higher wind speeds than deposition. A brief sensitivity analysis of the major influencing factors in Rome is shown in Figure 4: Both, deposition and resuspension fluxes are very sensitive to changes in LAI and deposition velocity, which had been modified 


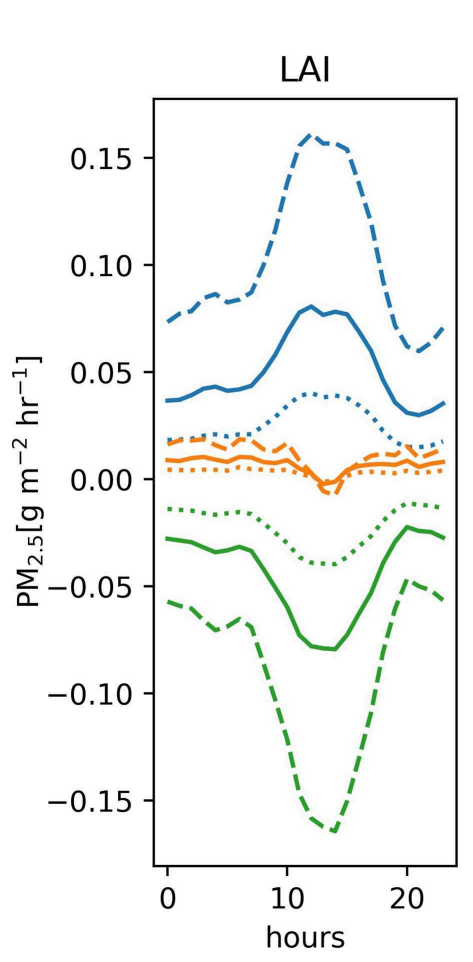

Parameter 0.5 -- 1 - 2 ..
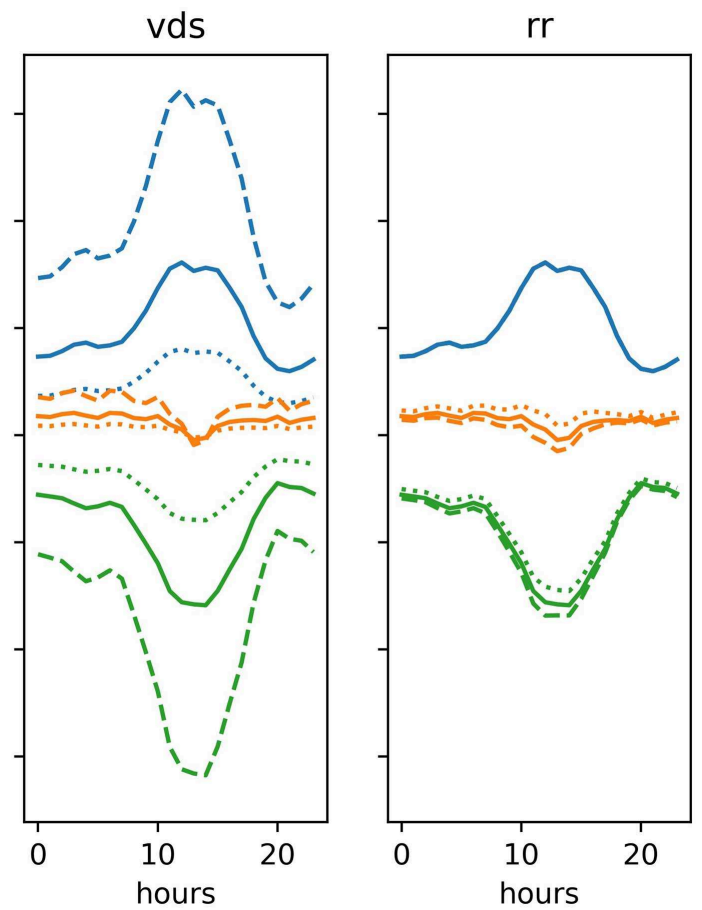

FIGURE 4 | Sensitivity of deposition (blue lines), net removal (orange), and resuspension (green) to parameter changes of leaf area index (LAl, left), specific deposition velocity (vds, middle), and resuspension percentages (rr, right). All simulations were run with half, normal and double values relative to standard parameters in the i-Tree Eco model (LAl: 3; vds: 0.2; rr see Tables S1, S2). All simulations are carried out for Rome in 2014 (DOY 221-263) and 2015 (DOY 133-154; 177-224; 267-279) and presented as the average diurnal cycle.

by varying $v d s$ as demonstrated in Table S1. Changing the resuspension sensitivity to wind speed does not affect deposition at all and has only a relatively small effect on resuspension. This is because a larger flux rate leads to a new equilibrium with smaller amounts of deposited matter and thus to smaller absolute resuspension rates (and vice versa). A comparison between sites with corresponding simulations is shown in Figures S5-S7. The influence of assuming different thresholds at which the particulates are washed off is demonstrated in Figure 5 for different plws values: The results show again a relatively low sensitivity of overall results but subtle differences between the sites, indicating that the efficacy of a specific threshold is higher at sites with a more even precipitation pattern (Munich) than at sites with more heterogeneous rainfall distribution (Rome).

The higher $\mathrm{PM}_{2.5}$ concentration and wind speed promote a larger dry deposition in Berlin compared to the other cities. The effect is particularly expressed in winter and autumn, when repeated rainfall events also provide a regular washing of the leaves, increasing the overall effectiveness of conifers. Thus, the highest seasonal net removal rates calculated was for conifers in Berlin during the winter of $2014 / 2015$. Although pollution and wind speed are somewhat smaller, the overall net removal for broadleaf deciduous trees in Munich is almost as high in Berlin. Here, the reason is that summer precipitation in Munich is much higher and thus resuspension in summer is smaller. In Rome, resuspension during summer is particular high and wind speed is relatively low, both resulting a smaller $\mathrm{PM}_{2.5}$ removal compared to that in the other cities. In addition, the vegetation period in Rome is longer, starting early in spring and sometimes reaching into the winter period. Therefore, the spring removal rates in Rome are more similar for broadleaf deciduous and evergreen trees than those in the other two cities where leaves were not fully developed at the time.

\section{DISCUSSION AND CONCLUSIONS}

\section{Particulate-Matter Deposition and Comparison With Literature Data}

The $\mathrm{PM}_{2.5}$-deposition difference that we obtained from the model for leaves from conifers and broadleaf trees is quite similar to that reported by Chen et al. (2017), who found an accumulation of particles on conifers that was up to six times the amount of that on broadleaf trees measured in summer through autumn (with no distinction between evergreen and deciduous broadleaves). This result is related to leaf size, with smaller leaves being more effective per $\mathrm{m}^{2}$ leaf surface (Xu et al., 2017; Weerakkody et al., 2018b), and surface properties such as roughness (Shao et al., 2019) as well as the occurrence of hairs (trichomes) (Chen et al., 2017; Muhammad et al., 2019) and waxes (Wang et al., 2015). Findings are, however, not always homogeneous as for example Leonard et al. (2016) found less PM accumulation on small and needle-like leaves, 

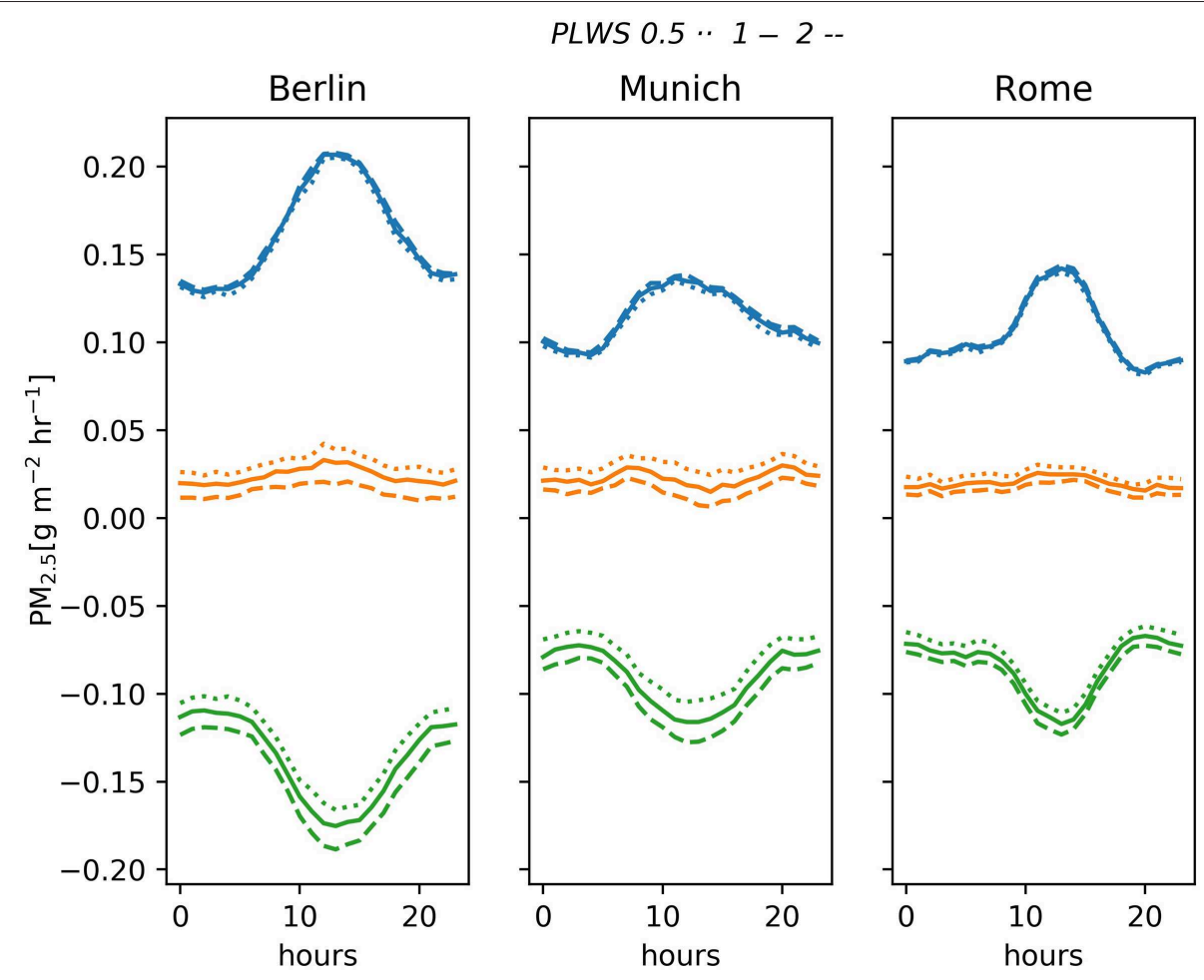

FIGURE 5 | Sensitivity of deposition (blue lines), net removal (orange), and resuspension (green) to parameter changes of potential leaf water storage (plws) shown for three different sites. All simulations are carried out for the period of 2013 and presented as the average diurnal cycle.

which might be related to the specific trait combination in the investigated species. In particular the occurrence of waxes, which are prominent in conifers, increases the deposition capacity due to their lipophilic properties that are able to bind particles composed of organic pollutants (Dzierzanowski et al., 2011). Since some broadleaved trees also develop waxes and particularly hairy trichomes such as for example Platanus acerifolia (Aiton) Willd. (Li et al., 2019), a large variation can be found in the literature. Chen et al. (2017) indicate that the accumulated $\mathrm{PM}_{2.5}$ for conifers is in the range of $10-30 \mu \mathrm{g} \mathrm{cm}^{-2}$ and for broadleaf trees, 3-17 $\mu \mathrm{g} \mathrm{cm}^{-2}$. Similar values are also found for the broadleaf-evergreen Holm oak (Quercus ilex L.) (Sgrigna et al., 2015), which accumulated 4,13 , and $2 \mu \mathrm{g} \mathrm{cm}^{-2}$ in January, August, and October, respectively.

On a site scale, the eddy-flux based particle exchange measurement carried out in Rome during a period that falls within the time period investigated here, were similar in range and pattern compared with our model results (Fares et al., 2013) although resuspension is calculated to be lower (see Figure S4). Since the net removal as indicted by the measurements is considerably negative, particles may not only originate from previous plant deposition but also from other surfaces in the vicinity (Yang et al., 2016).

In comparison with other model approaches, the differentiated parametrization also seems to be appropriate. For example, $\mathrm{PM}_{2.5}$ deposition in Leicester, UK, estimated with a Computational Fluid Dynamics model required a deposition velocity of $0.64 \mathrm{~cm} \mathrm{~s}^{-1}$ which is about 3 -fold the value used in i-Tree for the same wind speed as indicated in the study (Jeanjean et al., 2016). This indicates that the i-Tree underestimates deposition due to its too coarse parameterization (although other influences such as the differentiation of tree types have not been tested in this study).

\section{Effect of Weather Conditions on Dry Deposition and Resuspension}

The deposition of particles on tree leaves changes during the year because not only PM concentration but also weather conditions such as precipitation and wind speed affect the deposition and resuspension of particles on and from leaves (Mori et al., 2015). Thus, although the PM concentration is higher in all cities in the winter and autumn, the deposition does not always follow the same pattern. The models assume that sufficient rainfall resets the potential deposition storage to zero, and thus precipitation events are a precondition to enable particle removal over a prolonged period. For example, the effect dominated the simulations for the summer 2014 in Munich, as high precipitation continuously increased cumulative deposition. In contrast, long dry periods such as those that frequently occur in Rome lead to a high resuspension rate, decreasing the actual net PM removal. This is more evident when LAI is higher and rain events are not able to wash off particles from foliage, leaving a larger amount that can be resuspended. Another aspect that needs to be considered is that wind speed and PM concentration are generally negatively correlated diurnally, which may even lead to a net emission during mid-day when wind speed is highest [as visible for 
some parameter combinations for Rome (Figure 4) and Munich (Figure 5, Figures S5-S7)].

This highlights the importance of including more mechanistic processes into the PM removal calculation that account for species-specific and rainfall-intensity dependent variation. For example, it might be favorable to consider that rainfall intensities differ within a canopy, with upper-canopy layers wetted first and lower layers affected only after prolonged precipitation. For example, Xu et al. (2017) found that PM wash-off rates increase with cumulative rainfall up to a maximum amount of $12.5 \mathrm{~mm}$ of rain removing 51 to $70 \%$ of $\mathrm{PM}$ accumulation, with a small amount of particles still retained on the leaf surface. Also, the removal of deposited PM from leaves depends on species-specific properties, as trichomes, or rough surfaces hold PM much more tightly, requiring more water for washing off (Hofman et al., 2014; Blanusa et al., 2015; Xu et al., 2017).

\section{Structural and Seasonal Influences on Particle Deposition}

Conifers are well-known to remove more airborne PM than evergreen or deciduous broadleaved species (Sun et al., 2014; Khan and Perlinger, 2017; Zhang Z. et al., 2017). This is partly due to their crown shape, as cone-shaped conifers are commonly more exposed to turbulent air movements than spherical broadleaved trees (Beckett et al., 2000). Additionally, narrow conifer needles are more efficient capturing particles compared to flat leaves as expressed by the Stoke number, which describes the ability of stopping a particle in relation to the leaf characteristics (Beckett et al., 2000). Other leaf characteristics affect deposition and are specific to species rather than specific to coarsely lumped tree types. Such properties include in particular surface roughness and trichome as well as wax abundance (Sæbø et al., 2012; Räsänen et al., 2013; Chen et al., 2017; Muhammad et al., 2019). Another leaf characteristic that is mostly not considered in models is that deciduous-tree species differ in their leafing behavior, with most species establishing their leaves at the beginning of the vegetation period while some produce new leaves continuously. The latter type will thus also continuously refresh its deposition capacity.

\section{Model Limits and Potential Improvements}

Given the arguments for species- and size-specific differences, we can now define a number of uncertainties in the model approach. In particular, parameters could be selected specifically by tree type or species that are not currently differentiated (i.e., species-specific deposition velocities, resuspension, and washing threshold according to leaf characteristics). The importance of this issue, the connected uncertainty, as well as the potentially large impacts have been demonstrated before (Pace et al., 2018). For the most sensitive parameter which is PMdeposition velocity, it is important to distinguish at least between deciduous, broadleaf evergreen, and conifer trees (Khan and Perlinger, 2017). It should be noted, however, that a functional relation between velocity and wind speed that considers species level leaf traits would be preferable (Chiam et al., 2019). Other parts of the deposition process might also be improved although the overall effect seems to be relatively small (judged on the environmental conditions simulated). For example, the dependence of resuspension rates on wind speed might better be defined on a species level considering various foliage traits (Pullman, 2009; Buccolieri et al., 2018). Also, washing of deposited PM from leaves should principally depend on leaf properties in addition to amount, frequency, and intensity of rain and should not be represented by a single threshold value of rainfall per day (Weerakkody et al., 2018a). Finally, the calculation of deposition and net pollutant removal could be improved, considering a vertically distributed leaf area (e.g., Grote and Reiter, 2004), which could enable a differentiation into fractions of leaves subjected to specific wind speeds and intercepted precipitation (Teske and Thistle, 2004).

The suggested modifications can be easily introduced into existing approaches such as the i-Tree Eco model. Considering a differentiation of velocity functions by tree groups is likely to increase the accuracy of deposition results, which is particularly important if it is coupled to regional climate/air chemistry models (Cabaraban et al., 2013). If not coupled to a separate vegetation model, such air chemistry models simulate deposition velocity by estimating a number of resistances that do not depend on tree species properties (Khan and Perlinger, 2017). Thus, the uncertainty related to these simplified assumptions is very high, which has recently been criticized (Saylor et al., 2019). The results presented here may help to mend this problem by providing at least type specific dependencies as has been suggested by Hicks et al. (2016).

Another line of improvement should also be noted, which is the neglection of branch and bark surfaces in estimates of pollutant removal. While the deposition at these surfaces may be indeed negligible for conifers with needles that densely cover twigs and a canopy that shields stems from pollutants, it has been shown to be considerable at least for some deciduous trees (Xu et al., 2019). Neglecting this effect might lead to serious biases during winter. In principle, however, separately accounting for different surfaces and velocities in Equation (1) (that also need to be species- or tree-type specific) could serve to consider this term.

\section{Tree-Type Distribution in Europe and Species-Selection Criteria}

The efficiency of particle removal depends not only on speciesspecific properties but also on weather and air-pollution boundary conditions, which interact with vegetation period length. Judging different species regarding their ability to remove $\mathrm{PM}_{2.5}$ therefore requires evaluation of species-specific or treetype-specific properties in their particular growing conditions. Also, other ecosystem services such as the mitigation of air temperature extremes, and restriction from site conditions as for example shade tolerance and resistance against pollution may restrict the freedom of decisions and need to be considered. In this respect, it should be noted that evergreen trees are more abundant in Mediterranean cities than in northern regions, where deciduous trees are much more prominent (Grote et al., 2016). Deciduous trees are preferred along the roads because 
their shading effect is limited to the summer period while in the winter, higher radiation input is welcomed. Nevertheless, in order to increase the ecosystem service of air-pollution removal, conifers, and other evergreen trees might be planted more often in parks. With the simulations presented here, we provide some evidence that conifer trees would be particularly effective in cities with higher precipitation and wind speed such as Berlin, while long dry periods such as those that are frequently observed in Rome decrease the deposition capacity, particularly for conifers. This does not mean that conifers are not preferable in Rome too, if $\mathrm{PM}_{2.5}$ deposition would be the decisive criteria because they still remove at least about two times more particles than broadleaf evergreen and more than four times as much as broadleaf deciduous trees. However, since the modeled difference is not as large particularly during summer, other ecosystem services such as a higher transpiration rate and thus more cooling might be more decisive. The case study of Munich additionally demonstrates that conifers and other evergreens have limited advantages if the winter period is relatively dry and windy as in the simulated example years. In this case (similar to Rome in the summer), the deposition outside the vegetation period is low because of a high resuspension rate. Since shading in winter might also be a disadvantage, deciduous trees might thus be preferable at places where the pollution removal effect is not so urgently needed.

\section{Future Perspectives on Modeling PM Removal by Urban Trees}

Analysis of past published studies and current model calculations have demonstrated that the uncertainties in calculating PM deposition are particularly high with regard to deposition velocities and degree to which particles are stuck on leaf surfaces. For the first issue, it is recommended to determine speciesspecific deposition velocities by direct measurements at the leaf or canopy scale, e.g., by the eddy-covariance technique. To improve the second issue, experimental studies are needed that relate removal efficiency to the amount of water that hits the leaf surfaces. The precision of models can be further improved by using stratified canopies that provide layer-specific wind speed and precipitation.

Finally, we would like to point out that not only particles but also dangerous gases such as $\mathrm{O}_{3}, \mathrm{NO}_{2}$, and $\mathrm{SO}_{2}$ are deposited on or taken up by trees. Since uptake requires the consideration of stomatal conductance, the processes need to be connected

\section{REFERENCES}

Badeck, F. W., Bondeau, A., Böttcher, K., Doktor, D., Lucht, W., Schaber, J., et al. (2004). Responses of spring phenology to climate change. New Phytol. 162, 295-309. doi: 10.1111/j.1469-8137.2004.01059.x

Beckett, K. P., Freer-Smith, P. H., and Taylor, G. (1998). Urban woodlands: their role in reducing the effects of particulate pollution. Environ. Pollut. 99, 347-360. doi: 10.1016/S0269-7491(98)00016-5

Beckett, K. P., Freer-Smith, P. H., and Taylor, G. (2000). Particulate pollution capture by urban trees: effect of species and windspeed. Glob. Chang. Biol. 6, 995-1003. doi: 10.1046/j.1365-2486.2000.00376.x

Blanusa, T., Fantozzi, F., Monaci, F., and Bargagli, R. (2015). Leaf trapping and retention of particles by holm oak and other common tree species in to photosynthesis and water-use efficiency, which would then also allow estimation of the effects of other ecosystem services such as shading and evaporative cooling. Such a model, as has been recently suggested by Fares et al. (2019), can be coupled with meteorological and soil-water balance models in order to consider the effect of future climate changes (windstorms, intense precipitation, prolonged drought) on urban-trees performance.

\section{DATA AVAILABILITY STATEMENT}

Publicly available datasets were analyzed in this study. This data can be found here: https://www.sciencedirect.com/science/ article/pii/S0269749116310685?via\%3Dihub.

\section{AUTHOR CONTRIBUTIONS}

RP has designed and carried out the research, implemented the model code, and written major parts of the text. RG contributed significantly to the design, discussion and writing of the text and supervised the research.

\section{FUNDING}

This research was supported by the Graduate School for Climate and Environment (GRACE). We also acknowledge support by the Deutsche Forschungsgemeinschaft and Open Access Publishing Fund of Karlsruhe Institute of Technology.

\section{ACKNOWLEDGMENTS}

We thank the i-Tree support team and in particular David Nowak for assisting the model implementation, Silvano Fares for providing evaluation data, Francesco De Fino for his help in writing the code, Shade Amini, Gabriele Guidolotti, Chiara Baldacchini for the fruitful discussion on the methodology, Zhenyou Zhang for his help with the graphs, and the Graduiertenzentrum Weihenstephan of Technical University of Munich as well as the ENAGO company for the English editing.

\section{SUPPLEMENTARY MATERIAL}

The Supplementary Material for this article can be found online at: https://www.frontiersin.org/articles/10.3389/ffgc.2020. 00026/full\#supplementary-material

Mediterranean urban environments. Urban For. Urban Green 14, 1095-1101. doi: 10.1016/j.ufug.2015.10.004

Bréda, N. J. J. (2003). Ground-based measurements of leaf area index: a review of methods, instruments and current controversies. J. Exp. Bot. 54, 2403-2417. doi: $10.1093 /$ jxb/erg263

Buccolieri, R., Santiago, J.-L., Rivas, E., and Sanchez, B. (2018). Review on urban tree modelling in CFD simulations: aerodynamic, deposition and thermal effects. Urban For. Urban Green 31, 212-220. doi: 10.1016/j.ufug.2018. 03.003

Cabaraban, M. T. I., Kroll, C. N., Hirabayashi, S., and Nowak, D. J. (2013). Modeling of air pollutant removal by dry deposition to urban trees using a WRF/CMAQ/i-Tree Eco coupled system. Environ. Pollut. 176, 123-133. doi: 10.1016/j.envpol.2013.01.006 
Cai, M., Xin, Z., and Yu, X. (2017). Spatio-temporal variations in PM leaf deposition: a meta-analysis. Environ. Pollut. 231, 207-218. doi: 10.1016/j.envpol.2017.07.105

Calfapietra, C., and Cherubini, L. (2019). Green infrastructure: nature-based solutions for sustainable and resilient cities. Urban For. Urban Green 37, 1-2. doi: 10.1016/j.ufug.2018.09.012

Chen, L., Liu, C., Zhang, L., Zou, R., and Zhang, Z. (2017). Variation in tree species ability to capture and retain airborne fine particulate matter (PM2.5). Sci. Rep. 7, 1-11. doi: 10.1038/s41598-017-03360-1

Chiam, Z., Song, X. P., Lai, H. R., and Tan, H. T. W. (2019). Particulate matter mitigation via plants: understanding complex relationships with leaf traits. Sci. Tot. Environ. 688, 398-408. doi: 10.1016/j.scitotenv.2019.06.263

Drew, D. R., Barlow, J. F., and Cockerill, T. T. (2013). Estimating the potential yield of small wind turbines in urban areas: a case study for greater London, UK. J. Wind Eng. Ind. Aerod. 115, 104-111. doi: 10.1016/j.jweia.2013.01.007

Dzierzanowski, K., Popek, R., Gawronska, H., Saebø, A., and Gawronski, S. W. (2011). Deposition of particulate matter of different size fractions on leaf surfaces and in waxes of urban forest species. Int. J. Phytoremed. 13, 1037-1046. doi: 10.1080/15226514.2011.552929

Escudero, A., and Mediavilla, S. (2003). Decline in photosynthetic nitrogen use efficiency with leaf age and nitrogen resorption as determinants of leaf life span. J. Ecol. 91, 880-889. doi: 10.1046/j.1365-2745.2003.00818.x

European Commission (2008). Directive 2008/50/Ec on Ambient Air Quality and Cleaner Air for Europe.

European Commission (2015). Nature-Based Solutions \& Re-Naturing Cities. Luxembourg.

European Environment Agency (2018). Air Quality in Europe - 2018 Report. Luxembourg: European Environment Agency.

Fares, S., Alivernini, A., Conte, A., and Maggi, F. (2019). Ozone and particle fluxes in a Mediterranean forest predicted by the AIRTREE model. Sci. Tot. Environ. 682, 494-504. doi: 10.1016/j.scitotenv.2019.05.109

Fares, S., Matteucci, G., Scarascia Mugnozza, G., Morani, A., Calfapietra, C., Salvatori, E., et al. (2013). Testing of models of stomatal ozone fluxes with field measurements in a mixed Mediterranean forest. Atmos. Environ. 67, 242-251. doi: 10.1016/j.atmosenv.2012.11.007

Fares, S., Savi, F., Fusaro, L., Conte, A., Salvatori, E., Aromolo, R., et al. (2016). Particle deposition in a peri-urban Mediterranean forest. Environ. Pollut. 218, 1278-1286. doi: 10.1016/j.envpol.2016.08.086

Forrest, J., and Miller-Rushing, A. J. (2010). Toward a synthetic understanding of the role of phenology in ecology and evolution. Philos. Trans. R. Soc. B. Biol. Sci. 365, 3101-3112. doi: 10.1098/rstb.2010.0145

Freer-Smith, P. H., El-Khatib, A. A., and Taylor, G. (2004). Capture of particulate pollution by trees: a comparison of species typical of semi-arid areas and North American species. Water. Air. Soi. Pollut. 155, 173-187. doi: 10.1023/B:WATE.0000026521.99552.fd

Giannakopoulos, C., Le Sager, P., Bindi, M., Moriondo, M., Kostopoulou, E., and Goodess, C. M. (2009). Climatic changes and associated impacts in the Mediterranean resulting from a $2^{\circ} \mathrm{C}$ global warming. Glob. Planet. Change 68, 209-224. doi: 10.1016/j.gloplacha.2009.06.001

Gratani, L., and Varone, L. (2007). Plant crown traits and carbon sequestration capability by Platanus hybrida brot. in Rome. Landscape Urban Plan. 81, 282-286. doi: 10.1016/j.landurbplan.2007.01.006

Grote, R., and Reiter, I. M. (2004). Competition-dependent modelling of foliage biomass in forest stands. Trees Struct. Funct. 18, 596-607. doi: 10.1007/s00468-004-0352-9

Grote, R., Samson, R., Alonso, R., Amorim, J. H., Cariñanos, P., Churkina, G., et al. (2016). Functional traits of urban trees: air pollution mitigation potential. Front. Ecol. Environ. 14:1426. doi: 10.1002/fee.1426

Hansen, R., Olafsson, A. S., van der Jagt, A. P. N., Rall, E., and Pauleit, S. (2019). Planning multifunctional green infrastructure for compact cities: What is the state of practice? Ecol. Indic. 96, 99-110. doi: 10.1016/j.ecolind.2017.09.042

Hicks, B. B., Saylor, R. D., and Baker, B. D. (2016). Dry deposition of particles to canopies-a look back and the road forward. J. Geophys. Res. Atmosph. 121, 691-707. doi: 10.1002/2015JD024742

Hirabayashi, S., Kroll, C. N., and Nowak, D. J. (2015). i-Tree Eco Dry Deposition Model Descriptions. Available online at: http://www.itreetools.org/ eco/resources/iTree_Eco_Dry_Deposition_Model_Descriptions.pdf (accessed April 4, 2019).
Hofman, J., Wuyts, K., Van Wittenberghe, S., and Samson, R. (2014). On the temporal variation of leaf magnetic parameters: seasonal accumulation of leafdeposited and leaf-encapsulated particles of a roadside tree crown. Sci. Total Environ. 493, 766-772. doi: 10.1016/j.scitotenv.2014.06.074

Janhäll, S. (2015). Review on urban vegetation and particle air pollution - deposition and dispersion. Atmos. Environ. 105, 130-137. doi: 10.1016/j.atmosenv.2015.01.052

Jeanjean, A. P. R., Monks, P. S., and Leigh, R. J. (2016). Modelling the effectiveness of urban trees and grass on PM2.5 reduction via dispersion and deposition at a city scale. Atmos. Environ. 147, 1-10. doi: 10.1016/j.atmosenv.2016.09.033

Khan, T. R., and Perlinger, J. A. (2017). Evaluation of five dry particle deposition parameterizations for incorporation into atmospheric transport models. Geosci. Model Dev. 10, 3861-3888. doi: 10.5194/gmd-10-3861-2017

Klingberg, J., Konarska, J., Lindberg, F., Johansson, L., and Thorsson, S. (2017). Mapping leaf area of urban greenery using aerial LiDAR and ground-based measurements in Gothenburg, Sweden. Urban For. Urban Green 26, 31-40. doi: 10.1016/j.ufug.2017.05.011

Leonard, R. J., McArthur, C., and Hochuli, D. F. (2016). Particulate matter deposition on roadside plants and the importance of leaf trait combinations. Urban For. Urban Green 20, 249-253. doi: 10.1016/j.ufug.2016.09.008

Levy, J. I., and Hanna, S. R. (2011). Spatial and temporal variability in urban fine particulate matter concentrations. Environ. Pollut. 159, 2009-2015. doi: 10.1016/j.envpol.2010.11.013

Li, Y., Wang, S., and Chen, Q. (2019). Potential of thirteen urban greening plants to capture particulate matter on leaf surfaces across three levels of ambient atmospheric pollution. Int. J. Environ. Res. Public Health 16:402. doi: 10.3390/ijerph16030402

Lovett, G. M. (1994). Atmospheric deposition of nutrients and pollutants in North America: an ecological perspective. Ecol. Appl. 4, 629-650. doi: $10.2307 / 1941997$

Lu, S., Yang, X., Li, S., Chen, B., Jiang, Y., Wang, D., et al. (2018). Effects of plant leaf surface and different pollution levels on PM2.5 adsorption capacity. Urban For. Urban Green 34, 64-70. doi: 10.1016/j.ufug.2018. 05.006

Massetti, L., Petralli, M., Napoli, M., Brandani, G., Orlandini, S., and Pearlmutter, D. (2019). Effects of deciduous shade trees on surface temperature and pedestrian thermal stress during summer and autumn. Int. J. Biometeorol. 63, 467-479. doi: 10.1007/s00484-019-01678-1

Mori, J., Sæbø, A., Hanslin, H. M., Teani, A., Ferrini, F., Fini, A., et al. (2015). Deposition of traffic-related air pollutants on leaves of six evergreen shrub species during a Mediterranean summer season. Urban For. Urban Green 14, 264-273. doi: 10.1016/j.ufug.2015. 02.008

Muhammad, S., Wuyts, K., and Samson, R. (2019). Atmospheric net particle accumulation on 96 plant species with contrasting morphological and anatomical leaf characteristics in a common garden experiment. Atmos. Environ. 202, 328-344. doi: 10.1016/j.atmosenv.2019.01.015

Öztürk, M., Bolat, I., and Ergün, A. (2015). Influence of air-soil temperature on leaf expansion and LAI of Carpinus betulus trees in a temperate urban forest patch. Agric. Forest Meteorol. 200, 185-191. doi: 10.1016/j.agrformet.2014. 09.014

Pace, R., Biber, P., Pretzsch, H., and Grote, R. (2018). Modeling ecosystem services for park trees: sensitivity of i-Tree eco simulations to light exposure and tree species classification. Forests 9:89. doi: 10.3390/f9020089

Peters, E. B., McFadden, J. P., and Montgomery, R. A. (2010). Biological and environmental controls on tree transpiration in a suburban landscape. $J$. Geophys. Res. Biogeosci. 115, 1-13. doi: 10.1029/2009JG001266

Peters, K., and Eiden, R. (1992). Modelling the dry deposition velocity of aerosol particles to a spruce forest. Atmos. Environ. Part A. Gen. Top. 26, 2555-2564. doi: 10.1016/0960-1686(92)90108-W

Pullman, M. R. (2009). Conifer PM2.5 deposition and re-suspension in wind and rain events (Master thesis). Cornell University, Ithaka, NY, United States.

Räsänen, J. V., Holopainen, T., Joutsensaari, J., Ndam, C., Pasanen, P., Rinnan, A., et al. (2013). Effects of species-specific leaf characteristics and reduced water availability on fine particle capture efficiency of trees. Environ. Pollut. 183, 64-70. doi: 10.1016/j.envpol.2013.05.015

Sæbø, A., Popek, R., Nawrot, B., Hanslin, H. M., Gawronska, H., and Gawronski, S. W. (2012). Plant species differences in particulate matter 
accumulation on leaf surfaces. Sci. Total Environ. 427-428, 347-354. doi: 10.1016/j.scitotenv.2012.03.084

Saylor, R. D., Baker, B. D., Lee, P., Tong, D., Pan, L., and Hicks, B. B. (2019). The particle dry deposition component of total deposition from air quality models: right, wrong or uncertain? Tellus B: Chem. Phys. Meteorol. 71, 1-22. doi: 10.1080/16000889.2018.15 50324

Schaubroeck, T., Deckmyn, G., Neirynck, J., Staelens, J., Adriaenssens, S., Dewulf, J., et al. (2014). Multilayered modeling of particulate matter removal by a growing forest over time, from plant surface deposition to washoff via rainfall. Environ. Sci. Technol. 48, 10785-10794. doi: 10.1021/es5019724

Sgrigna, G., Sæbø, A., Gawronski, S., Popek, R., and Calfapietra, C. (2015). Particulate matter deposition on quercus ilex leaves in an industrial city of central Italy. Environ. Pollut. 197, 187-194. doi: 10.1016/j.envpol.2014. 11.030

Shao, F., Wang, L., Sun, F., Li, G., Yu, L., Wang, Y., et al. (2019). Study on different particulate matter retention capacities of the leaf surfaces of eight common garden plants in Hangzhou, China. Sci. Tot. Environ. 652, 939-951. doi: 10.1016/j.scitotenv.2018.10.182

Sun, F., Yin, Z., Lun, X., Zhao, Y., Li, R., Shi, F., et al. (2014). Deposition velocity of PM2.5 in the winter and spring above deciduous and coniferous forests in Beijing, China. PLoS ONE 9:e97723. doi: 10.1371/journal.pone.0097723

Teske, M. E., and Thistle, H. W. (2004). A library of forest canopy structure for use in interception modeling. For. Ecol. Manage. 198, 341-350. doi: 10.1016/j.foreco.2004.05.031

Tigges, J., Churkina, G., and Lakes, T. (2017). Modeling above-ground carbon storage: a remote sensing approach to derive individual tree species information in urban settings. Urban Ecosyst. 20, 97-111. doi: 10.1007/s11252-016-0585-6

Tiwary, A., Williams, I. D., Heidrich, O., Namdeo, A., Bandaru, V., and Calfapietra, C. (2016). Development of multi-functional streetscape green infrastructure using a performance index approach. Environ. Pollut. 208, 209-220. doi: 10.1016/j.envpol.2015. 09.003

Wang, L., Gong, H., Liao, W., and Wang, Z. (2015). Accumulation of particles on the surface of leaves during leaf expansion. Sci. Total Environ. 532, 420-434. doi: 10.1016/j.scitotenv.2015.06.014

Weerakkody, U., Dover, J. W., Mitchell, P., and Reiling, K. (2018a). The impact of rainfall in remobilising particulate matter accumulated on leaves of four evergreen species grown on a green screen and a living wall. Urban For. Urban Green 35, 21-31. doi: 10.1016/j.ufug.2018.07.018
Weerakkody, U., Dover, J. W., Mitchell, P., and Reiling, K. (2018b). Quantification of the traffic-generated particulate matter capture by plant species in a living wall and evaluation of the important leaf characteristics. Sci. Tot. Environ. 635, 1012-1024. doi: 10.1016/j.scitotenv.2018.04.106

World Health Organization (2006). Health Risks of Particulate Matter From LongRange Transboundary Air Pollution. Copenhagen: World Health Organization, Regional Office for Europe.

World Health Organization (2013). Health Effects of Particulate Matter. Policy Implications for Countries in Eastern Europe, Caucasus and Central Asia. Copenhagen: World Health Organization, Regional Office for Europe.

Xiao, Q., Ma, Z., Li, S., and Liu, Y. (2015). The impact of winter heating on air pollution in China. PLoS ONE 10:e0117311. doi: 10.1371/journal.pone.0117311

Xu, X., Yu, X., Mo, L., Xu, Y., Bao, L., and Lun, X. (2019). Atmospheric particulate matter accumulation on trees: a comparison of boles, branches and leaves. $J$. Clean. Prod. 226, 349-356. doi: 10.1016/j.jclepro.2019.04.072

Xu, X., Zhang, Z., Bao, L., Mo, L., Yu, X., Fan, D., et al. (2017). Influence of rainfall duration and intensity on particulate matter removal from plant leaves. Sci. Tot. Environ. 609, 11-16. doi: 10.1016/j.scitotenv.2017. 07.141

Yang, Y., Vance, M., Tou, F., Tiwari, A., Liu, M., and Hochella, M. F. (2016). Nanoparticles in road dust from impervious urban surfaces: distribution, identification, and environmental implications. Environ. Sci. Nano 3, 534-544. doi: $10.1039 / \mathrm{C} 6 \mathrm{EN} 00056 \mathrm{H}$

Zhang, W., Wang, B., and Niu, X. (2017). Relationship between leaf surface characteristics and particle capturing capacities of different tree species in Beijing. Forests 8, 1-12. doi: 10.3390/f8030092

Zhang, Z., Liu, J., Wu, Y., Yan, G., Zhu, L., and Yu, X. (2017). Multi-scale comparison of the fine particle removal capacity of urban forests and wetlands. Sci. Rep. 7, 1-13. doi: 10.1038/srep46214

Conflict of Interest: The authors declare that the research was conducted in the absence of any commercial or financial relationships that could be construed as a potential conflict of interest.

Copyright $\odot 2020$ Pace and Grote. This is an open-access article distributed under the terms of the Creative Commons Attribution License (CC BY). The use, distribution or reproduction in other forums is permitted, provided the original author(s) and the copyright owner(s) are credited and that the original publication in this journal is cited, in accordance with accepted academic practice. No use, distribution or reproduction is permitted which does not comply with these terms. 